Enhanced phycocyanin and protein content of Arthrospira by applying neutral density and red light shading filters: a small-scale pilot experiment Peer-reviewed author version

Kilimtzidi, Evmorfia; Cuellar Bermudez, Sara; Markou, Giorgos; Goiris, Koen; VANDAMME, Dries \& Muylaert, Koenraad (2019) Enhanced phycocyanin and protein content of Arthrospira by applying neutral density and red light shading filters: a small-scale pilot experiment. In: JOURNAL OF CHEMICAL TECHNOLOGY AND BIOTECHNOLOGY, 94 (6), p. 2047-2054.

DOI: $10.1002 /$ jctb.5991

Handle: http://hdl.handle.net/1942/28491 


\section{Enhanced phycocyanin and protein content of Arthrospira by applying neutral density and red light shading filters: a small-scale pilot experiment}

Evmorfia Kilimtzidi $^{1^{*}}$, Sara Cuellar Bermudez ${ }^{1}$, Giorgos Markou ${ }^{2}$, Koen Goiris ${ }^{3 \dagger}$, Dries Vandamme $^{4}$, Koenraad Muylaert ${ }^{1}$

${ }^{1}$ KU Leuven Campus Kortrijk, Laboratory Aquatic Biology, E. Sabbelaan 53, 8500 Kortrijk, Belgium

${ }^{2}$ Institute of Technology of Agricultural Products, Hellenic Agricultural OrganizationDemeter (ELGO-Demeter), Leof. Sofokli Venizelou 1, Likovrisi, 141 23, Athens,

Greece

${ }^{3}$ KU Leuven Technology Campus Ghent, Laboratory of Enzyme Fermentation and Brewing Technology, Gebroeders De Smetstraat 1, 9000 Ghent, Belgium

${ }^{4}$ Hasselt University Campus Diepenbeek, Institute for Materials Research (IMO-

IMOMEC), Laboratory of Applied and Analytical Chemistry, Martelarenlaan 42, 3500

Hasselt, Belgium

*Corresponding author: $\quad$ E-mail :evmorfia.kilimtzidi@kuleuven.be

Tel: +32485379049

${ }^{\dagger}$ Deceased on June 242017

This article has been accepted for publication and undergone full peer review but has not been through the copyediting, typesetting, pagination and proofreading process, which may lead to differences between this version and the Version of Record. Please cite this article as doi: $10.1002 / \mathrm{jctb} .5991$ 


\begin{abstract}
BACKGROUND : The cyanobacterium Arthrospira contains proteins and the blue pigment phycocyanin that can be used as a natural colorant in the food industry. The aim of this study was to investigate a strategy to increase the yield of phycocyanin and protein from Arthrospira cultures by shading the cultures with neutral density and red light filters. Experiments were conducted under three different irradiance conditions, (i) lab tests under relatively low light (LL) intensities $\left(100 \mu \mathrm{mol} \mathrm{m} \mathrm{m}^{-2} \mathrm{~s}^{-1}\right.$ ), (ii) lab tests under relatively high light (HL) intensities $\left(516 \mu \mathrm{mol} \mathrm{m}^{-2} \mathrm{~s}^{-1}\right)$, and (iii) scaled-up tests under natural (NL) conditions by cultivating Arthrospira in raceway-ponds in a greenhouse.
\end{abstract}

RESULTS : In all cases, shading of cultures with red filters resulted in biomass with increased phycocyanin content achieving a maximum of 134,71 and $121 \mathrm{mg} \mathrm{g}^{-1}$ under low light, high light intensity and natural conditions, respectively. Under high light intensity and natural conditions, shaded cultures displayed phycocyanin of higher purity and increased protein content, which reached up to 43 and $65 \%$, respectively.

CONCLUSIONS : Shading of Arthrospira cultures by low-cost polyester red light filters may be an effective way to enhance phycocyanin production and improve its purity in outdoor 'spirulina farms'.

Keywords : Arthrospira platensis ; Spirulina ; phycobiliproteins ; colouring foodstuffs ; C-phycocyanin

This article is protected by copyright. All rights reserved. 


\section{NOTATION}

HL

High light intensity

LL

Low light intensity

NL

Natural conditions

PAR

Photosynthetically active radiation

\section{INTRODUCTION}

Microalgae (including cyanobacteria) are an attractive biomass feedstock for the production of high-value bio products ${ }^{1}$. One of the most important high-value products derived from microalgae on the market today is the natural blue dye phycocyanin ${ }^{2}$. Phycocyanin is a phycobiliprotein pigment with a bright blue colour that is used as a natural colourant in various sweets and drinks ${ }^{3}$. Demand for phycocyanin has increased in recent years because synthetic colourants are increasingly being replaced by natural colourants in the food industry, mostly due to real or perceived negative health effects of synthetic colourants ${ }^{4}$. Phycocyanin may even have positive health effects because it possesses antioxidant, anticancer, neuroprotective and anti-inflammatory properties 5 .

The main commercial source of phycocyanin today is the cyanobacterium Arthrospira (commonly known as Spirulina) ${ }^{6}$. Phycocyanin is extracted from dried Arthrospira biomass using water-based solvents and further purified and concentrated from these extracts using various methods such as ammonium sulphate precipitation, polyethylene glycol separation, ultrafiltration and/or chromatography ${ }^{3}$. Extraction and purification of phycocyanin is a complex process that involves several drying and 
separation steps ${ }^{7}$. As a result, the cost of phycocyanin is determined to a larger extent by the cost of processing than by the cost of the Arthrospira biomass feedstock ${ }^{8}$. Because the energy and chemical demand required for processing is inversely related to the concentration of the product in the biomass feedstock ${ }^{9}$, the cost of phycocyanin could be reduced by using Arthrospira biomass that is enriched in phycocyanin.

Moreover, due to the increasing trend of world demand of food and feed protein, microalgae have been suggested as an important alternative source for proteins ${ }^{10}$. In particular, the biomass of Arthrospira is rich in proteins (up to 60-70\%), carbohydrates, minerals and vitamins ${ }^{6,11}$. The protein content in the biomass can be altered due to changes in the light intensity and light regimes ${ }^{12}$. More specifically, low light intensities are known to stimulate the protein production in Arthrospira biomass ${ }^{12}$. Although the impact of light intensity or spectral composition of the light on the protein content in Arthrospira biomass has been investigated, the results reported in literature are conflicting. On the one hand, some studies suggest that the protein content in Arthrospira is increased when the light intensities are low ${ }^{13,14}$, while others reported that higher light intensities stimulate protein production ${ }^{15}$. Changes in the spectral composition of the light are also known to affect the protein content ${ }^{16}$.

In current extensive cultivation systems for Arthrospira biomass production, culture conditions are not optimized to maximize the phycocyanin or protein content and the concentration of phycocyanin in the biomass is relatively low, from only 27 to maximum $96 \mathrm{mg} \mathrm{g}^{-1}$ in commercial biomass samples ${ }^{11}$. It is well-known that cyanobacteria adjust their phycobiliprotein pigment concentration in response to changes in the light intensity and light quality ${ }^{17}$. In general, the changes in the phycobiliproteins are reflected in the number and size of these pigments ${ }^{18,19}$. In a study

This article is protected by copyright. All rights reserved. 
by Nomsawai (1999), it was reported that the amount of phycobiliproteins was increased when Arthrospira cultures were transferred from high to low light intensities ${ }^{19}$. This increase was caused by the change in the rate of biosynthesis of the phycobiliproteins ${ }^{19}$. In Arthrospira, the concentration of phycocyanin in the biomass is generally increased when light levels are low in order to increase light harvesting efficiency ${ }^{19,20}$. In fact, under low light levels, the total pigment concentration is increased for the cells to absorb more light, whilst under high light levels the excess light cannot be utilized by the cells, and therefore is lost as heat or fluorescence ${ }^{20}$. Cyanobacteria also adjust the phycocyanin concentration to changes in the spectral composition of the light, a phenomenon that is known as chromatic adaptation ${ }^{21}$. Because phycocyanin absorbs light in the red part of the spectrum with a maximum absorbance at $620 \mathrm{~nm}^{22}$, the concentration of phycocyanin should increase under red light conditions. Several studies have reported changes in the phycocyanin concentration in Arthrospira biomass under different light wavelengths generated by LED lights. These experiments, however, have yielded contrasting results: while some studies found the highest phycocyanin concentration under blue light illumination $16,23,24$, others found a higher phycocyanin concentration under red light illumination ${ }^{25}$. In these studies, phycocyanin concentrations of up to $175 \mathrm{mg} \mathrm{g}^{-1}$ have been reported 16,26

While previous studies have shown that coloured LED lights can be used to produce Arthrospira biomass that is enriched in phycocyanin, this method cannot be implemented in existing extensive outdoor production facilities due to the high cost of energy required for illumination with artificial lighting ${ }^{27}$. Moreover, since under natural conditions the stronger illuminated outer cell layers have a high (80\%) dissipation of

This article is protected by copyright. All rights reserved. 
light energy as unused thermal energy by activating photoprotective mechanisms (like non-photochemical quenching), resulting in overall low photosynthetic efficiencies ${ }^{28}$. Therefore, in some cases it could be beneficial to shade the cultures in order to reduce photoinhibition processes. To these ends, the aim of this study was to test whether similarly high concentrations of phycocyanin can be achieved by shading cultures with light filters, which might be a significantly less expensive way than artificial lighting. Light filters are a low-cost solution that might be easily implemented in existing open pond production facilities.

\section{MATERIALS AND METHODS}

\section{Arthrospira strain and culture conditions}

The strain Arthrospira platensis SAG 21.99 (further referred to as Arthrospira) was used in all experiments. The strain was cultured in $1 \mathrm{~L}$ bottles in autoclaved Zarrouk's medium as modified by Cogne et al $^{29}$. Nitrogen concentration in this medium is very high (about $400 \mathrm{mg} \mathrm{NO}_{3}-\mathrm{N} \mathrm{L}^{-1}$ ). As a result, nitrogen stress and the accompanying decline in phycocyanin concentration in the biomass are avoided ${ }^{5}$.

\section{Experimental set - up}

\section{Low light intensity experiment}

In the low light intensity experiment (LL), Arthrospira was cultured in $1 \mathrm{~L}$ bottles that were covered with red and neutral density (grey) light filters; the non - covered bottles were used as a control. The treatments were inoculated at an initial $\mathrm{OD}_{750}$ of 0.06 , corresponding to a biomass concentration of $0.055 \mathrm{~g} \mathrm{~L}^{-1}$. Cultures were stirred using a 
magnetic stirrer (200 rpm) and bubbled with $0.2 \mu \mathrm{m}$ filtered air. The photoperiod was set at 16:8 h light: dark. Cultures were maintained in a temperature-controlled room at a constant temperature of $22{ }^{\circ} \mathrm{C}$. Light was provided by daylight fluorescent tubes that emit light across the PAR range of the light spectrum (Lumilux HE 840, OSRAM, Germany). The light intensity in the control cultures was $100 \mu \mathrm{mol}$ photons $\mathrm{m}^{-2} \mathrm{~s}^{-1}$ at the surface of the bottles.

\section{High light intensity experiment}

The experimental set-up of the high light intensity experiment (HL) was similar to the one of the low light intensity experiment. In this experiment, light was supplied by a white cool LED lamp $100 \mathrm{~W}$ (Led Flood Light, Brennenstuhl, Germany) that generates white light across the light spectrum. Light intensity at the surface of the control cultures was $516 \mu \mathrm{mol}$ photons $\mathrm{m}^{-2} \mathrm{~s}^{-1}$.

\section{Scaled-up tests under natural conditions (NL)}

The scaled -up experiment was carried out in a greenhouse at Provinciaal Proefcentrum voor de Groenteteelt (Kruishoutem) in Belgium. The experiment was performed in July, when the average daytime temperatures were above $25{ }^{\circ} \mathrm{C}$, whilst during the night temperatures ranged from 13 to $18{ }^{\circ} \mathrm{C}$. Arthrospira was cultured in $32 \mathrm{~L}$ raceway pond reactors containing $20 \mathrm{~L}$ of culture medium. The length/width ratio of the raceway pond reactors was 1.3 and the water column depth was $20 \mathrm{~cm}$. The treatments were inoculated at an average initial $\mathrm{OD}_{750}$ of 0.15 corresponding to a biomass concentration of $0.14 \mathrm{~g}$ $\mathrm{L}^{-1}$. Two of the ponds were covered with red and neutral density (grey) light filters and the non - covered pond was used as the control (Fig.1). The cultures were agitated using 
paddle wheels, whose speed was adjusted to $30 \mathrm{~Hz}$. The light intensity was measured daily using a quantum sensor (Full spectrum quantum sensor SQ 500, Apogee Instruments, USA). The daytime average light intensity in the surface of the ponds varied from 437 to $1406 \mu \mathrm{mol}$ photons $\mathrm{m}^{-2} \mathrm{~s}^{-1}$.

\section{Light filters}

To evaluate the influence of light filters on optical density, quantum yield, phycocyanin purity and productivity, as well as biomass productivity and composition, control cultures receiving the full light intensity were compared between cultures covered with red and neutral density light filters. Experiments (LL and HL) were carried out in duplicates in $1 \mathrm{~L}$ glass bottles that were wrapped with polyester light filters; noncovered bottles were used as a control.

Light filters made from polyester were purchased from Lee (UK). The neutral density filter (LEE 209) is a grey filter that modifies the light intensity equally across the light spectrum. The red light filter (LEE 287) partially blocks the transmittance of blue light. The spectra of the light transmitted by the filters were measured using a spectrophotometer (Genesys 10S UV-Vis, Thermo-Scientific, USA) (Supplementary data ; Fig.S2). The average blue (400 to $450 \mathrm{~nm}$ ) and red (550 to $650 \mathrm{~nm})$ light transmitted by the red filter was 3 and 53, respectively, while by the grey filter this was 39 and 42 , respectively. The total PAR irradiance ( 400 to $700 \mathrm{~nm}$ ), the average blue and red irradiance in the control treatments and treatments with red and neutral density filters were measured using a spectroradiometer for the LL, HL and NL experiments (STS radiometer, OceanOptics, USA) (Table 1, Supplementary data ; Fig.S3). The total PAR in the control treatments was higher for the NL than for the HL experiment, and 
PAR in the HL experiment was in turn higher than the LL experiment. Because the light spectrum of the two artificial light sources used in the experiments deviates from the solar irradiance spectrum, the ratio of blue over red light intensity was higher in NL conditions than in artificial light conditions (HL and LL). The red light filter resulted in a decrease in the blue to red light ratio in all experiments, but this decrease was stronger in the LL and NL experiment than in the HL experiment. The blue to red light ratio transmitted by the grey filter was slightly higher than in control conditions in experiments with artificial light (LL and HL) and slightly lower than control conditions in the natural light experiment (NL).

\section{Biomass analyses}

In all experiments, biomass in the cultures was monitored spectrophotometrically as optical density at $750 \mathrm{~nm}\left(\mathrm{OD}_{750}\right)$ (Genesys $10 \mathrm{~S}$ UV-Vis, Thermo-Scientific, USA) ${ }^{30}$. Spectrophotometric biomass estimates were calibrated using gravimetric dry weight analysis $\left(\mathrm{g} \mathrm{L}^{-1} \mathrm{DW}=0.918 \times \mathrm{OD}_{750}, \mathrm{r}^{2}=0.99, \mathrm{n}=10\right)$. The maximum quantum yield (Fv/Fm) was measured using a Pulse Amplitude Modulated fluorometer (AquaPen AP100, Photon Systems Instruments, Czech Republic). The maximum quantum yield of photosystem II is a parameter that shows the stress in photosynthetic organisms ${ }^{31}$. Fm indicates the maximal fluorescence, Fo the minimum fluorescence and Fv (Fm-Fo) the variable. Before the measurements, the cells were dark - adapted for $30 \mathrm{~min}^{31}$.

At the end of each experiment, on day 10, a subsample was collected for gravimetric analysis of the dry weight biomass concentration. Therefore, a known volume of culture was filtered on a pre-weighed GF/C filter followed by drying at 110 ${ }^{\circ} \mathrm{C}$ for $24 \mathrm{~h}$. The final dry weight biomass concentration was considered as the biomass

This article is protected by copyright. All rights reserved. 
production of the culture. The remaining suspension was harvested using a $20 \mu \mathrm{m}$ pore size nylon mesh, washed with distilled water and immediately stored at $-80^{\circ} \mathrm{C}$. The frozen Arthrospira biomass was freeze-dried and phycocyanin, proteins, carbohydrates, chlorophyll a and carotenoids were measured in the freeze-dried biomass. Proteins were determined by the Lowry assay ${ }^{32}$ and carbohydrates using the phenol-sulphuric acid method according to Dubois with glucose as standard ${ }^{33}$. Carotenoids and total chlorophyll in the biomass were measured according to the method by Lichtenthaler ${ }^{34}$.

\section{Analytical determination of phycocyanin concentration in the biomass}

The dry biomass was diluted in $0.1 \mathrm{M}$ phosphate buffer solution $\mathrm{pH}$ 6. Subsequently, the solution was mixed and incubated in a warm water bath at $30^{\circ} \mathrm{C}$ for 16 hours. After incubation, the solution was centrifuged $\left(20 \mathrm{~min}, 10{ }^{\circ} \mathrm{C}, 3400 \mathrm{x} \mathrm{g}\right)$ and the supernatant containing the phycocyanin was collected. At this point, the absorbance of the supernatant was measured at 620, 650 and $280 \mathrm{~nm}$. Phycocyanin (c-phycocyanin) concentration was calculated as described by the method of Yoshikawa and Belay ${ }^{35}$ : phycocyanin $\left(\mathrm{mg} \mathrm{L}^{-1}\right)=0.162 \times \mathrm{OD}_{620}-0.098 \times \mathrm{OD}_{650}$ where $\mathrm{OD}_{620}$ and $\mathrm{OD}_{650}$ are the optical absorption at the wavelengths of 620 and 650 $\mathrm{nm}$, respectively. The purity of phycocyanin (c-phycocyanin) was estimated from the ratio $\mathrm{OD}_{620} / \mathrm{OD}_{280}{ }^{36}$.

\section{Statistical analysis}

Differences in biomass productivity, biomass composition, phycocyanin concentration, purity and productivity in the cultures were compared between the different treatments using one-way ANOVA. To check for pairwise differences between the treatments, a

This article is protected by copyright. All rights reserved. 
Tukey's post-hoc test was used. A p-level of 0.05 was considered to be significant. Statistical analyses were performed with the R software.

\section{RESULTS AND DISCUSSION}

\section{Effect of light filters on biomass productivity}

Fig.2 illustrates the kinetics of optical density (an indirect way to determine the biomass concentration in the medium) and the final biomass productivity of the different treatments. In the LL runs, shading of cultures with light filters resulted in a decline in the optical density when compared to the control cultures. This was expected since the total irradiance used $\left(100 \mu \mathrm{mol} \mathrm{m} \mathrm{m}^{-2} \mathrm{~s}^{-1}\right)$ was well below the light saturation level (around $200 \mu \mathrm{mol} \mathrm{m}^{-2} \mathrm{~s}^{-1}$ for Arthrospira ${ }^{37}$ ), and therefore any reduction of the light intensity would result in the decline in productivity. In the HL intensity runs, the optical density and the final biomass productivity of the cultures did not differ significantly $(p=0.67)$ between the treatments $\left(\mathrm{HL}, 516 \mu \mathrm{mol} \mathrm{m} \mathrm{m}^{-2} \mathrm{~s}^{-1}\right)$. In this experiment the irradiance was higher than the saturation level and, therefore, a reduction in light intensity through shading with filters does not negatively affect biomass growth. This is due to the fact that at light intensities that surpass light saturation, the excess light energy that is absorbed from the photosynthetic machinery cannot be metabolically utilized and is dissipated and lost either as thermal energy or as fluorescence. At much higher light intensities photoinhibition could occur, a phenomenon that typically occurs under natural conditions and lowers photosynthetic efficiency ${ }^{38}$.

However, in the experiments conducted under natural conditions (NL runs) shading of cultures caused a decrease in optical density and biomass productivity, 
despite the fact that light intensity was higher than in the HL experiment (437 -1406 $\mu \mathrm{mol} \mathrm{m} \mathrm{m}^{-1}$ ). Despite the fact that light intensity at the surface of the reactors was higher, the average light intensity in the reactor as experienced by microalgae can be much lower due to self-shading of the cultures by microalgal cells ${ }^{39,40}$. Reactors used in laboratory experiments were of cylindrical shape with $9 \mathrm{~cm}$ diameter and irradiation from one side (it was assumed that irradiation at the non-illuminated side was $25 \%$ of that at the illuminated side), while ponds had $20 \mathrm{~cm}$ depth and only irradiation from the surface. Based on the Beer-Lambert law, the geometry of the experimental vessels and the extinction coefficient derived from the biomass concentration, we estimated the average light intensity in each series of experiments (supplementary data ; Fig.S4). From these estimates it is clear that the average irradiance experienced by microalgae in the ponds is lower than for the HL experiments and is actually more similar to the LL experiment.

Maximum quantum yield of primary photochemistry, which is the ratio of variable fluorescence to the maximum fluorescence $\left(\mathrm{F}_{\mathrm{V}} / \mathrm{F}_{\mathrm{m}}\right)$ is frequently used as an indicator of the performance of photosystem II, a major component of the photosynthetic machinery ${ }^{41}$. In Fig.3 the maximum quantum yield of primary photochemistry (QY) of the various experimental treatments is illustrated. Runs of LL and NL did not display any differences between the controls and the shaded cultures, reflecting that in all these cases Arthrospira was not stressed due to high light levels. In contrast, in the runs with HL, the shaded cultures had higher QY than the control, revealing that under these conditions the unshaded Arthrospira was negatively affected by the high light intensity while shading of cells reduced the stress associated to high light intensities. These results are in line with the observations of biomass productivity 
where it was observed that HL runs, even illuminated with lower light intensities than in NL runs, (ponds) cells were under higher light stress, and thus any shading of the cultures lead to the mitigation of light stress. In open ponds operated under natural conditions, even cells are subjected in photoinhibitory light levels, during agitation, cells are propelled towards the dark layers of the ponds (depths more than $5 \mathrm{~cm}$ ), where Photosystem II (PSII) activity recovers rapidly in the dark ${ }^{42}$. Ponds have generally longer dark periods than photobioreactors leading thus higher levels of recovery ${ }^{43}$. This conclusion is supported as well from the results on the quantum yields of primary photochemistry.

\section{Effect of light filters on phycocyanin concentration and productivity}

In all conditions (LL, HL and NL) shading of cultures with red light filters caused an increase in phycocyanin concentration (Fig.4). In particular, in LL at day 10 phycocyanin reached a maximum of $134 \mathrm{mg} \mathrm{g}^{-1}$ and $122 \mathrm{mg} \mathrm{g}^{-1}$ in the red and grey light filters, respectively, whilst the content of the control was $110 \mathrm{mg} \mathrm{g}^{-1}$. Under HL conditions the differences were much larger, giving 71,58 and $23 \mathrm{mg} \mathrm{g}^{-1}$ at day 10 for red, grey and control runs, respectively. Same trend of phycocyanin content was observed as well in NL runs, where at day 10, red filter gave the highest phycocyanin content $\left(121 \mathrm{mg} \mathrm{g}^{-1}\right)$, followed by grey $\left(113 \mathrm{mg} \mathrm{g}^{-1}\right)$ and the control $\left(99 \mathrm{mg} \mathrm{g}^{-1}\right)$. Between the different light conditions, the highest phycocyanin content was obtained under LL, followed by NL, while HL gave significantly lower values. These results are in agreement with previous observations that both a reduction in the light quantity ${ }^{13,24,44}$ or change on light quality (light spectrum towards red) ${ }^{24,25,45}$ can induce an increase in the phycocyanin concentration in Arthrospira biomass. This observation can be

This article is protected by copyright. All rights reserved. 
explained by the capacity of chromatic adaptation of many cyanobacteria, including Arthrospira, in which cyanobacteria adjust their pigment composition in response to light alterations ${ }^{21}$. Phycocyanin absorbs light in wavelengths where chlorophyll a poorly absorbs, and light energy absorbed by phycocyanin is transferred to chlorophyll a in photosystem II to enhance the photosynthetic capacity of Arthrospira ${ }^{22}$. The chromatic adaptation is reflected by the increase in phycocyanin concentration when the cultures were shaded with red light filters. Red coloured filters yielded the highest phycocyanin concentrations in both laboratory conditions and in the greenhouse under natural conditions. As concerns the neutral density filter treatments, the increase in phycocyanin content can only be the result of changes in the light quantity, as the spectral composition of the light was not modified.

Under LL and NL conditions, although in the cultures covered with light filters the biomass productivity was significantly lower compared to the controls, the increase of phycocyanin content led to a similar phycocyanin productivity of the cultures $(\mathrm{p}=$ 0.16). The use of light filters to enhance phycocyanin production is clearly a more effective strategy when the average light intensity to which Arthrospira cells are exposed is high, as is evident from the strong increase in phycocyanin concentration in the shaded cultures in the HL experiment. When light intensity is high, shading the cultures by light filters also does not result in a decrease in biomass productivity.

\section{Effect of light filters on phycocyanin purity}

Fig. 5 displays the phycocyanin purity of the different treatments during the experimental time course. In the LL runs, the purity of phycocyanin did not differ significantly between the light filter treatments and the control. Under HL conditions,

This article is protected by copyright. All rights reserved. 
phycocyanin purity declined from days 1-3 in all cultures and then from days 3-8 increased for the light filter treatments, whilst it decreased for the control treatment. Similarly, in the NL runs phycocyanin purity of the control culture was lower than in the cultures covered with light filters throughout the time course of the experiment. In general, similarly to phycocyanin concentration, phycocyanin purity is higher in the LL runs, followed by NL, and then by HL runs that showed the lowest phycocyanin purity in all treatments. Additionally, under HL and NL runs, the phycocyanin extract from the control biomass displayed lower purity than the extracts of the red and grey light filter biomass. As a result, the quality of the phycocyanin extract is higher when light filters are used as opposed to the control that might lead to lower cost of processing (compound extraction) and higher price.

\section{Effect of light filters on the biomass composition}

The effect of shading of the cultures of Arthrospira with coloured filters on the biomass composition is shown in Table 2. Regarding proteins, shading of cultures under HL condition led to an increase in protein content giving $42 \%, 43 \%$ for the red and grey filters, respectively against $31 \%$ of the control. Similarly, in the NL runs, the protein content increased from $53 \%$ in the control culture to $58 \%$ in the red and $65 \%$ in the grey light filters' cultures. So far, there are several studies suggesting that the protein content is subject to changes in the light intensity and/or spectral composition of the light ${ }^{13,15,46,47}$. In the study by Dejsungkranont et al., ${ }^{13}$ the proteins in Arthrospira biomass were decreased from $23 \%$ to $15 \%$ with increasing light intensities (from 101 to $203 \mu \mathrm{mol} \mathrm{m} \mathrm{s} \mathrm{s}^{-1}$ ). These results are in agreement with the present study. In contrast, Ogbonda et al., found that proteins in Arthrospira increased with increase in light

This article is protected by copyright. All rights reserved. 
intensity ${ }^{15}$. However, in this study, the light intensities used were much lower than the ones used in the present study, comparing artificial light ranging from 7.5 to $15 \mu \mathrm{mol} \mathrm{m}$ ${ }^{2} \mathrm{~s}^{-1}$ to sunlight.

Regarding carbohydrates, under LL conditions, carbohydrate content was not affected by shading the cultures. By contrast, under HL conditions, shading the cultures with light filters led to a significant reduction in carbohydrates content compared to the control culture (Table 2). This is in general in line with previous studies, which demonstrate that higher light intensities result in higher carbohydrate content ${ }^{48,49}$. In a study by Lee et al., the maximum carbohydrate content (11\%) was obtained under high light intensities $\left(192 \mu \mathrm{mol} \mathrm{m} \mathrm{s}^{-1}\right)^{50}$. Similarly, De Philipps et al., observed an increase in the carbohydrate content from 7-10\% to 34\% in Arthrospira maxima when light levels were increased ${ }^{51}$. In the HL runs, the chlorophyll content was significantly higher in the cultures shaded with light filters, giving $1.2 \%$ for the red and grey filters and only $0.6 \%$ for the control, which corresponds to a $50 \%$ increase in chlorophyll content. These results come in line with previous studies ${ }^{52}$, where it was shown that a reduction in chlorophyll content of several micro algal species was observed upon increase in the light intensity ${ }^{53}$ or by changing the light wavelengths ${ }^{54}$. Carotenoids did not show any significant differences in none of the experiments, indicating that they are not influenced by differences in light intensity.

\section{CONCLUSIONS}

The present study demonstrates that shading of Arthrospira cultures with light filters, although it might decrease biomass productivity, causes an increase in protein and phycocyanin content. Regarding phycocyanin, shaded cultures displayed an enhanced

This article is protected by copyright. All rights reserved. 
phycocyanin purity and productivity under high light intensity and natural conditions. Especially red coloured filters gave the best results when light intensities were the highest investigated in laboratory conditions or when Arthrospira was cultivated in a greenhouse under natural conditions. Hence, shading Arthrospira cultures with red light filters could be a feasible strategy for improving protein and phycocyanin content and purity of the produced biomass.

\section{ACKNOWLEDGEMENTS}

The authors would like to thank Research Foundation Flanders (FWO, grant numbers: 1S16118N and 12D8917N) and EU Interreg V Vlaanderen-Nederland project 'De Blauwe Keten' for funding this research.

\section{REFERENCES}

1. Mata TM, Martins AA and Caetano NS, Microalgae for biodiesel production and other applications: A review. Renew Sustain Energy Rev 14:217-232 (2010).

2. Eriksen NT, Research Trends in the Dominating Microalgal Pigments, $\beta$ carotene, Astaxanthin, and Phycocyanin Used in Feed, in Foods, and in Health Applications. J Nutr Food Sci 06:1-6 (2016).

3. Sekar S and Chandramohan M, Phycobiliproteins as a commodity: Trends in applied research, patents and commercialization. J Appl Phycol 20:113-136 (2008).

4. Rahman DY, Sarian FD, Van Wijk A, Martinez-Garcia M and Van der Maarel MJEC,Thermostable phycocyanin from the red microalga Cyanidioschyzon 
merolae, a new natural blue food colorant. J Appl Phycol 29:1233-1239 (2017).

5. Eriksen NT, Production of phycocyanin - A pigment with applications in biology, biotechnology, foods and medicine. Appl Microbiol Biotechnol 80:1-14 (2008).

6. Spolaore P, Joannis-Cassan C, Duran E and Isambert A, Commercial applications of microalgae. J Biosci Bioeng 101:87-96 (2006).

7. Manirafasha E, Ndikubwimana T, Zeng X, Lu Y and Jing K, Phycobiliprotein: Potential microalgae derived pharmaceutical and biological reagent. Biochem Eng J 109:282-296 (2016).

8. Patil G, Chethana S, Sridevi AS and Raghavarao KSMS, Method to obtain Cphycocyanin of high purity. J Chromatogr A 1127:76-81 (2006).

9. Chisti Y, Pneumatically Agitated Bioreactors in Industrial and Environmental Bioprocessing: Hydrodynamics, Hydraulics, and Transport Phenomena. Appl Mech Rev 51:33-112 (1998).

10. Becker EW, Micro-algae as a source of protein. Biotechnol Adv 25:207-210 (2007).

11. Campanella L, Crescentini G and Avino P, Chemical composition and nutritional evaluation of some natural and commercial food products based on Spirulina. Analusis 27:533-540 (1999).

12. Soni RA, Sudhakar K and Rana RS, Spirulina - From growth to nutritional product: A review. Trends Food Sci Technol 69:157-171 (2017).

13. Dejsungkranont M, Chisti Y and Sirisansaneeyakul S, Simultaneous production of C-phycocyanin and extracellular polymeric substances by photoautotrophic cultures of Arthrospira platensis. J Chem Technol Biotechnol 92:2709-2718 (2017).

This article is protected by copyright. All rights reserved. 
14. Chaiklahan R, Khonsarn N, Chirasuwan N, Ruengjitchatchawalya M, Bunnag B and Tanticharoen M, Response of Spirulina platensis C1 to High Temperature and High Light Intensity. Kasetsart J - Nat Sci 41:123-129 (2007).

15. Ogbonda $\mathrm{KH}$, Aminigo RE and Abu GO, Influence of aeriation and lighting on biomass production and protein biosynthesis in a Spirulina sp. isolated from an oil-polluted brackish water marsh in the Niger Delta, Nigeria. J Biotechnol 6 :2596-2600 (2007).

16. Markou G, Effect of various colors of light-emitting diodes (LEDs) on the biomass composition of Arthrospira platensis cultivated in semi-continuous mode. Appl Biochem Biotechnol 172:2758-2768 (2014).

17. Grossman AR, Bhaya D and He Q, Tracking the Light Environment by Cyanobacteria and the Dynamic Nature of Light Harvesting. J Biol Chem 276 :11449-11452 (2001).

18. Glazer AN, Phycobilisome: a macromolecular complex for light energy transfer. Biochim Biophys Acta 768:29-51 (1981).

19. Nomsawai P, Tandeau De Marsac N, Thomas JC, Tanticharoen M and Cheevadhanarak S, Light Regulation of Phycobilisome Structure and Gene Expression in Spirulina platensis C1 (Arthrospira sp. PCC 9438). Plant Cell Physiol 40:1194-1202 (1999).

20. Xue S, Su Z and Cong W, Growth of Spirulina platensis enhanced under intermittent illumination. J Biotechnol 151:271-277 (2011).

21. Bennett A and Bogorad L, Complementary Chromatic Adaptation in a Filamentous Blue-Green Alga. J Cell Biol 58:419-435 (1973).

22. MacColl R, Cyanobacterial phycobilisomes. J Struct Biol 124:311-334 (1998).

This article is protected by copyright. All rights reserved. 
23. Akimoto S, Yokono M, Hamada F, Teshigahara A, Aikawa S and Kondo A, Adaptation of light-harvesting systems of Arthrospira platensis to light conditions, probed by time-resolved fluorescence spectroscopy. Biochim Biophys Acta - Bioenerg 1817:1483-1489 (2012).

24. Chen HB, Wu JY, Wang CF, Fu CC, Shieh CJ, Chen CI et al., Modeling on chlorophyll a and phycocyanin production by Spirulina platensis under various light-emitting diodes. Biochem Eng J 53:52-56 (2010).

25. Yim SK, Ki DW, Doo HS, Kim H and Kwon TH, Internally illuminated photobioreactor using a novel type of light-emitting diode (LED) bar for cultivation of Arthrospira platensis. Biotechnol Bioprocess Eng 21:767-776 (2016).

26. Patel A, Mishra S, Pawar R and Ghosh PK, Purification and characterization of C-Phycocyanin from cyanobacterial species of marine and freshwater habitat. Protein Expr Purif 40:248-255 (2005).

27. Ooms MD, Dinh CT, Sargent EH and Sinton D, Photon management for augmented photosynthesis. Nat Commun 7:1-13 (2016).

28. Goldman JC, Outdoor Algal Mass Cultures - II. Photosynthetic Yield Limitations. Water Res 13:119-136 (1979).

29. Cogne G, Lehmann B, Dussap CG and Gros JB, Uptake of macrominerals and trace elements by the cyanobacterium Spirulina platensis (Arthrospira platensis PCC 8005) under photoautotrophic conditions: Culture medium optimization. Biotechnol Bioeng 81:588-593 (2003).

30. Griffiths MJ, Garcin C, Van Hille RP and Harrison STL, Interference by pigment in the estimation of microalgal biomass concentration by optical density. $J$ 
Microbiol Methods 85:119-123 (2011).

31. Parkhill JP, Maillet G and Cullen JJ, Fluorescence-based maximal quantum yield for PSII as a diagnostic of nutrient stress. J Phycol 37:517-529 (2001).

32. Lowry OH, Rosebrough NJ, Farr AL and Randall BJ, Protein measurement with the Folin phenol reagent. J Biol Chem 193:265-275 (1951).

33. Dubois M, Gilles KA, Hamilton JK, Rebers PA and Smith F, Colorimetric method for determination of sugars and related substances. Anal Chem 28:350 $356(1956)$

34. Lichtenthaler HK, Chlorophylls and carotenoids: Pigments of photosynthetic biomembranes, in Methods in Enzymology, ed by Packer L and Douce R. Elsevier, California, pp. 350-382 (1987).

35. Yoshikawa N and Belay A, Single-laboratory validation of a method for the determination of c-Phycocyanin and Allophycocyanin in Spirulina (Arthrospira) supplements and raw materials by spectrophotometry. J AOAC Int 91:524-529 (2008).

36. Herrera A, Boussiba S and Napoleone V, Recovery of c-phycocyanin from the cyanobacterium Spirulina maxima. Appl Phycol 1:325-331 (1989).

37. Lu C and Vonshak A, Effects of salinity stress on photosystem II function in cyanobacterial Spirulina platensis cells. Physiol Plant 114:405-413 (2002).

38. Lu C and Vonshak A, Photoinhibition in outdoor Spirulina platensis cultures assessed by polyphasic chlorophyll fluorescence transients. J Appl Phycol 11 :355-359 (1999).

39. Chen CY, Yeh KL, Aisyah R, Lee DJ and Chang JS, Cultivation, photobioreactor design and harvesting of microalgae for biodiesel production: A critical review.

This article is protected by copyright. All rights reserved. 
Bioresour Technol 102:71-81 (2011).

40. Magro FG, Margarites AC, Reinehr CO, Gonçalves GC, Rodigheri G, Costa JAV et al., Spirulina platensis biomass composition is influenced by the light availability and harvest phase in raceway ponds. Environ Technol 39: 1868-1877 (2018).

41. Masojídek J, Vonshak A and Torzillo G, Chlorophyll Fluorescence Applications in Microalgal Mass Cultures, in Chlorophyll a Fluorescence in Aquatic Sciences: Methods and Applications, ed by Suggett D, Prášil O and Borowitzka M. Springer, Dordrecht, pp 277 - 292 (2010).

42. Shyam R, Raghavendra AS and Sane PV, Role of dark respiration in photoinhibition of photosynthesis and its reactivation in the cyanobacterium Anacystis nidulans. Physiol Plant 88:446-452 (1993).

43. Demory D, Combe C, Hartmann P, Talec A, Pruvost E, Hamouda R et al., How do microalgae perceive light in a high-rate pond? Towards more realistic Lagrangian experiments. $R$ Soc Open Sci 5 :180523 (2018). http://dx.doi.org/10.1098/rsos.180523

44. Wang CY, Fu CC and Liu YC, Effects of using light-emitting diodes on the cultivation of Spirulina platensis. Biochem Eng J 37:21-25 (2007).

45. Lima GM, Teixeira PCN, Teixeira CMLL, Filócomo D and Lage CLS, Influence of spectral light quality on the pigment concentrations and biomass productivity of Arthrospira platensis. Algal Res 31:157-166 (2018).

46. Coward T, Fuentes-Grünewald C, Silkina A, Oatley-Radcliffe DL, Llewellyn G and Lovitt RW, Utilising light-emitting diodes of specific narrow wavelengths for the optimization and co-production of multiple high-value compounds in

This article is protected by copyright. All rights reserved. 
Porphyridium purpureum. Bioresour Technol 221:607-615 (2016).

47. Seyfabadi J, Ramezanpour Z and Khoeyi ZA, Protein, fatty acid, and pigment content of Chlorella vulgaris under different light regimes. J Appl Phycol $\mathbf{2 3}$ :721-726 (2011).

48. Markou G, Angelidaki I and Georgakakis D, Microalgal carbohydrates: An overview of the factors influencing carbohydrates production, and of main bioconversion technologies for production of biofuels. Appl Microbiol Biotechnol 96:631-645 (2012).

49. Olguín EJ, Galicia S, Angulo-Guerrero O and Hernández E, The effect of low light flux and nitrogen deficiency on the chemical composition of Spirulina $s p$. (Arthrospira) grown on digested pig waste. Bioresour Technol 77:19-24 (2001).

50. Lee MC, Chen YC and Peng TC, Two-stage culture method for optimized polysaccharide production in Spirulina platensis. J Sci Food Agric 92:1562-1569 (2012).

51. De Philippis R, Sili C and Vincenzini M, Glycogen and poly- $\beta$-hydroxybutyrate synthesis in Spirulina maxima. J Gen Microbiol 138:1623-1628 (1992).

52. He Q, Yang $\mathrm{H}, \mathrm{Wu} \mathrm{L}$ and $\mathrm{Hu} \mathrm{C}$, Effect of light intensity on physiological changes, carbon allocation and neutral lipid accumulation in oleaginous microalgae. Bioresour Technol 191:219-228 (2015).

53. Jespersen L, Strømdahl LD, Olsen K and Skibsted LH, Heat and light stability of three natural blue colorants for use in confectionery and beverages. Eur Food Res Technol 220:261-266 (2005).

54. Mohsenpour SF, Richards B and Willoughby N, Spectral conversion of light for enhanced microalgae growth rates and photosynthetic pigment production.

This article is protected by copyright. All rights reserved. 
Bioresour Technol 125:75-81 (2012).

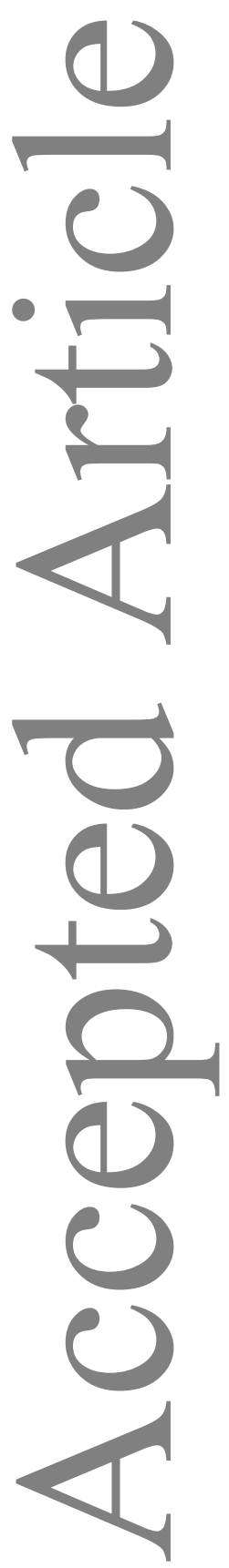

This article is protected by copyright. All rights reserved. 


\section{Tables captions}

Table 1. Overview of the light intensity and light spectrum in the control, red and grey filter treatments in the experiments with low light (LL), high light (HL) and natural light (NL). The light spectrum was measured with a spectroradiometer. The PAR irradiance transmitted by the filters and received at the surface of the bottles/ponds, as well as the average blue (400 to $450 \mathrm{~nm}$ ) and red (550 to $650 \mathrm{~nm}$ ) light received compared to the control cultures (as measured with a spectroradiometer) are given for each treatment and each experiment. The PAR irradiance in the ponds is the average irradiance received in the surface of the ponds during daylight hours over the course of the experiment, while the spectrum was measured during clear sky conditions.

Table 2. The biomass composition of Arthrospira between the different treatments under low light and high light intensities, as well as under natural conditions is presented.

This article is protected by copyright. All rights reserved. 
Table 1.

\begin{tabular}{|c|c|c|c|}
\hline Experiments & Control & Red filter & Grey filter \\
\hline \multicolumn{4}{|l|}{ LL experiment } \\
\hline PAR $\left(\mu \mathrm{mol} \mathrm{m} \mathrm{m}^{-2} \mathrm{~s}^{-1}\right)$ & 100 & 40 & 30 \\
\hline Red light & 5.5 & 3.3 & 2.0 \\
\hline Blue light & 1.4 & 0.07 & 0.60 \\
\hline Ratio blue : red light & 0.25 & 0.02 & 0.30 \\
\hline \multicolumn{4}{|l|}{ HL experiment } \\
\hline PAR $\left(\mu \mathrm{mol} \mathrm{m}{ }^{-2} \mathrm{~s}^{-1}\right)$ & 516 & 206 & 155 \\
\hline Red light & 24.6 & 11.0 & 7.4 \\
\hline Blue light & 8.0 & 1.1 & 2.8 \\
\hline Ratio blue : red light & 0.32 & 0.10 & 0.38 \\
\hline \multicolumn{4}{|l|}{ NL experiment } \\
\hline $\operatorname{PAR}\left(\mu \mathrm{mol} \mathrm{m} \mathrm{m}^{-2}\right)$ & 1072 & 429 & 322 \\
\hline Red light & 401 & 230 & 173 \\
\hline Blue light & 222 & 5 & 59 \\
\hline Ratio blue : red light & 0.55 & 0.02 & 0.34 \\
\hline
\end{tabular}

This article is protected by copyright. All rights reserved. 


\section{Table 2.}

\begin{tabular}{|c|c|c|c|c|}
\hline Experiments & Proteins (\%) & $\begin{array}{c}\text { Carbohydrates } \\
(\%)\end{array}$ & Chlorophyll (\%) & Carotenoids (\%) \\
\hline \multicolumn{5}{|l|}{ LL exp. } \\
\hline Control & $58.3 \pm 3.8^{\mathrm{a}}$ & $8.4 \pm 1.3^{\mathrm{a}}$ & $2.1 \pm 0.3^{\mathrm{a}}$ & $0.50 \pm 0.05^{\mathrm{a}}$ \\
\hline Red & $62.4 \pm 4.0^{\mathrm{a}}$ & $9.3 \pm 0.7^{\mathrm{a}}$ & $2.3 \pm 0.05^{\mathrm{a}}$ & $0.48 \pm 0.01^{\mathrm{a}}$ \\
\hline Grey & $59.4 \pm 6.5^{\mathrm{a}}$ & $10.2 \pm 1.7^{\mathrm{a}}$ & $2.2 \pm 0.09^{\mathrm{a}}$ & $0.48 \pm 0.01^{\mathrm{a}}$ \\
\hline \multicolumn{5}{|l|}{ HL exp. } \\
\hline Control & $30.7 \pm 1.4^{\mathrm{c}}$ & $31.8 \pm 1.1^{\mathrm{c}}$ & $0.6 \pm 0.05^{c}$ & $0.31 \pm 0.02^{b}$ \\
\hline Red & $41.7 \pm 5.0^{\mathrm{b}}$ & $18.7 \pm 4.6^{\mathrm{b}}$ & $1.2 \pm 0.22^{b}$ & $0.36 \pm 0.04^{b}$ \\
\hline Grey & $42.7 \pm 5.4^{\mathrm{b}}$ & $19.5 \pm 19.5^{\mathrm{b}}$ & $1.2 \pm 0.19^{b}$ & $0.38 \pm 0.05^{b}$ \\
\hline \multicolumn{5}{|l|}{ NL exp. } \\
\hline Control & 53.2 & 5.1 & 1.9 & 0.44 \\
\hline Red & 57.7 & 5.6 & 1.7 & 0.38 \\
\hline Grey & 65.2 & 4.8 & 2.1 & 0.44 \\
\hline
\end{tabular}

*Means \pm standard deviations. Different letters in the same column indicate significant statistical differences between the different treatments at a $95 \%$ confidence level $(p=0.05)$.

This article is protected by copyright. All rights reserved. 


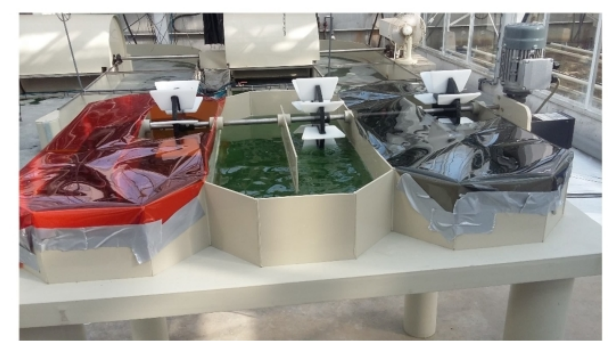

Fig.1 The experimental set-up of the raceway pond reactors in the greenhouse. Arthrospira was cultivated under natural conditions in the ponds covered with red and grey light filters and the non-covered pond was used as a control.

$254 \times 142 \mathrm{~mm}(300 \times 300 \mathrm{DPI})$

This article is protected by copyright. All rights reserved. 

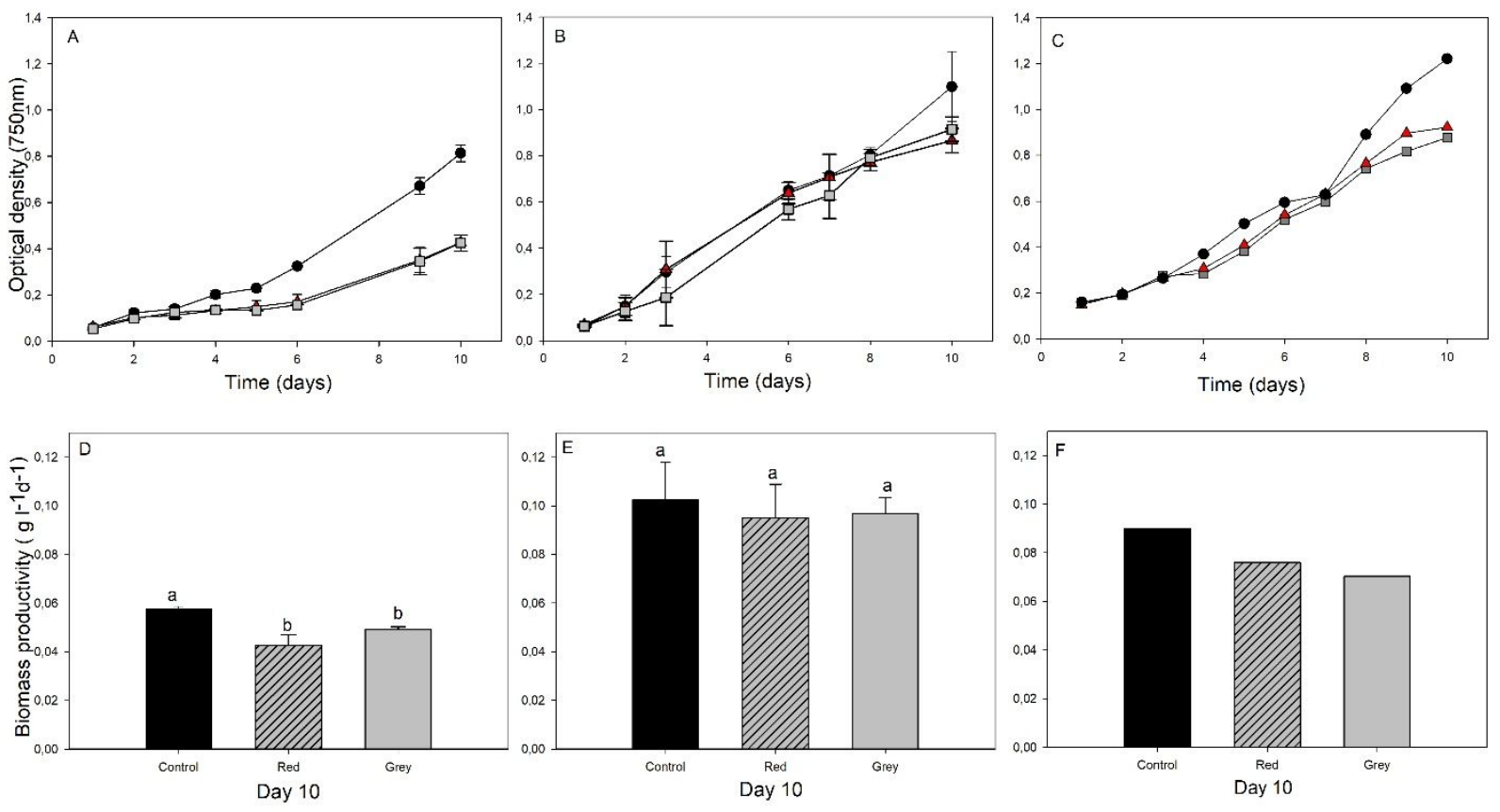

Fig. 2 Optical density (A-C) in the LL, HL and NL experiments, respectively. The light filter treatments were compared to the control treatment for a period of 10 days (control : $\mathbf{O}$; red : $\mathbf{\Delta}$; grey : $\square$ ). Differences in biomass productivity $\left(\mathrm{g} \mathrm{L}^{-1} \mathrm{~d}^{-1}\right)$ between the light filters and the control treatment were compared at the last day of the experiment (D : LL, E: HL, F : NL). Statistically significant differences between the treatments in graphs $\mathrm{D}$ and $\mathrm{E}$ are indicated by different letters $(p=0.05)$

Fig. 2 was created using SigmaPlot 11.

This article is protected by copyright. All rights reserved. 


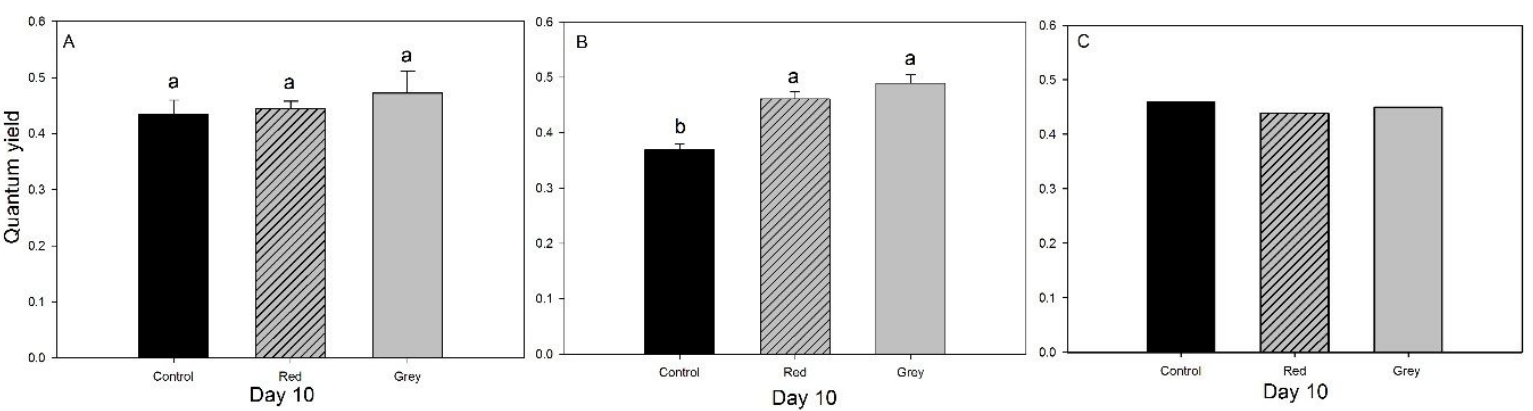

Fig. 3 Quantum yield (A-C) in the LL, HL and NL experiments, respectively, where the light filter treatments were compared to the control treatment at the last day of the experiment.

Fig.3 was created in SigmaPlot 11.

This article is protected by copyright. All rights reserved. 

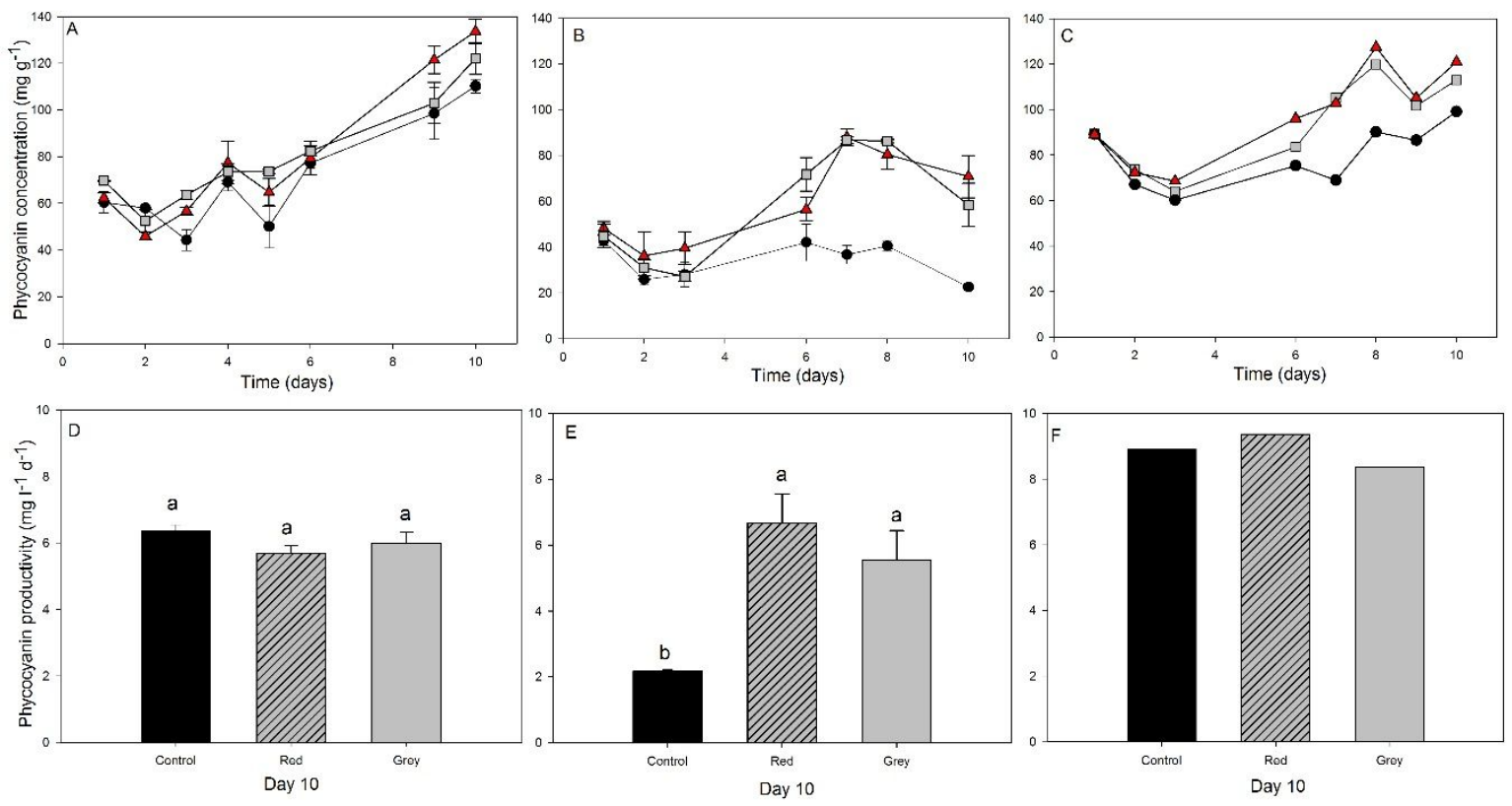

Fig.4 Phycocyanin concentration $\left(\mathrm{mg} \mathrm{g}^{-1}\right)(\mathrm{A}-\mathrm{C})$ in the LL, HL and NL experiments, respectively. The light filter treatments were compared to the control treatment for a period of 10 days (control : $\mathbf{O}$; red : $\boldsymbol{\Delta}$; grey : $\square$ ). Differences in phycocyanin productivity $\left(\mathrm{mg} \mathrm{l}^{-1} \mathrm{~d}^{-1}\right)$ (D-F) between the light filters and the control treatment (D : LL, E: HL, F : NL) were compared at the last day of the experiment. Statistically significant differences between the treatments in graphs D and E are indicated by different letters $(\mathrm{p}=0.05)$.

Fig.4 was originally created in SigmaPlot 11.

This article is protected by copyright. All rights reserved. 

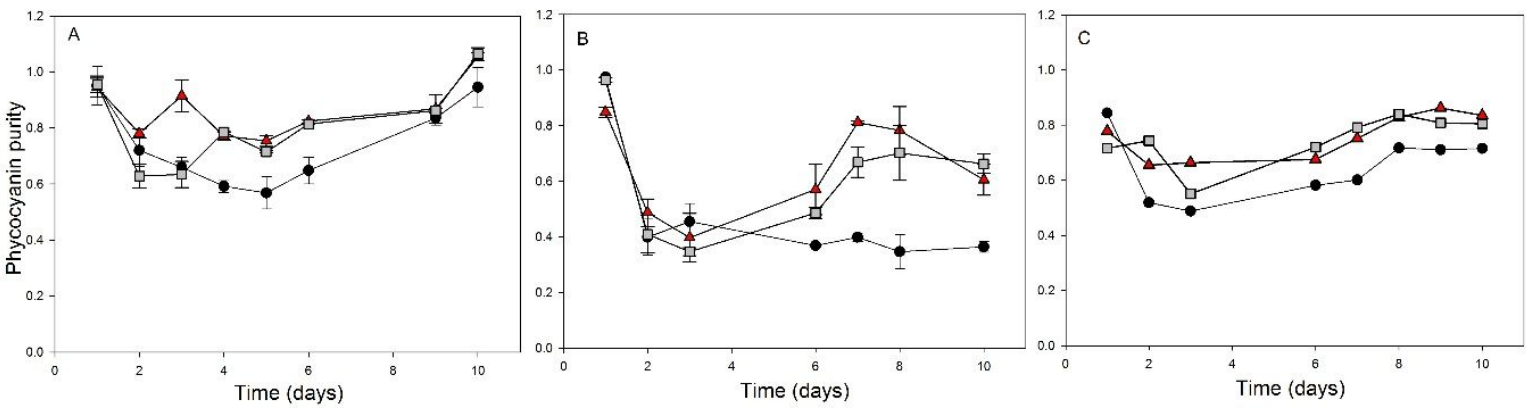

Fig.5 Phycocyanin purity (A-C) in the LL, HL and NL experiments, respectively. The light filter treatments were compared to the control treatment for a period of 10 days (control : red : $\Delta$; grey : $\square)$

Fig.5 was created using SigmaPlot 11.

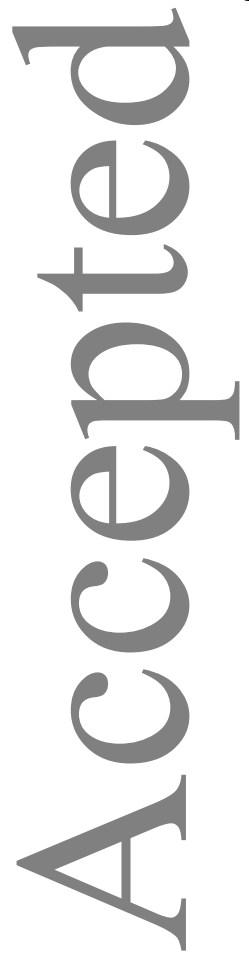

This article is protected by copyright. All rights reserved. 